\title{
Topology structures of the families of gray images
}

\section{N. $\mathrm{Wu}^{1}$}

\begin{abstract}
Let L be a subspace of Euclidean Space $E^{1}$. $\downarrow$ USC(X,L) denote all regions below of upper semi-continuous maps from $X$ to $L$ and $\downarrow C(X, L)$ denote all regions below of continuous maps from $X$ to $L$. For an infinite compact metric space X, $\downarrow$ USC(X,I) with Vietoris topology is homeomorphic to Hilbert cube Q and $\downarrow \mathrm{C}(\mathrm{X}, \mathrm{I})$ is its subspace, where $\mathrm{Q}=[-1,1] \infty$. $\downarrow \mathrm{USC}(\mathrm{X}, \mathrm{I})$ could be regarded as a mathematical model of all gray images. In the present paper, the following result is proved: $\downarrow$ USC $(\mathrm{X},[0,1))$ is homeomorphic to $\mathrm{Q} \backslash\{(0)\}$. Therefore the topological structure of $\downarrow \mathrm{C}(\mathrm{X},[0,1))$ is also clear.
\end{abstract}

Keywords: Upper semi-continuous maps. Continuous maps. Vietoris topology. Regions below of maps. Hilbert cube.

\subsection{Introduction}

For a Tychonoff space $\mathrm{X}$, the hyperspace $\mathrm{Cld}(\mathrm{X})$ is the set consisting of all nonempty closed subsets of $\mathrm{X}$ endowed with the Vietoris topology which is generated by the subbase $\left\{U^{-}, U^{+}: U \subset X\right.$ is open $\}$, where $U^{-}=\{A \in C l d(X) \mid A \cap U \neq \varnothing\}$ and $U^{+}=\{A \in C l d(X) \mid A \subset U\}$, where $U$ is open in $X$. Thus $\left\{<U_{1}, U_{2}, \ldots, U_{n}>\right.$ : $\mathrm{Ui}$ is open in $\mathrm{X}\}$ is a base for this topology, where $<U_{1}, U_{2}, \ldots, U_{n}>=\{A \in$ $\operatorname{Cld}(X): A \subset \bigcup_{i=1}^{n} U_{i}$ and $A \cap U_{i} \neq \varnothing$ for each $\left.i=1,2, \ldots, n\right\}$.

It is well-known that $\mathrm{Cld}(\mathrm{X})$ with this topology is metrizable if and only if $\mathrm{X}$ is compact and metrizable [1, Theorem I.3.4]. For a compact space $\mathrm{X}$ and for any admissible metric $d$ on $X$, the Vietoris topology of $\operatorname{Cld}(X)$ is induced by the Hausdorff metric $\mathrm{d}_{\mathrm{H}}$ defined as follows:

\footnotetext{
${ }^{1}$ N. Wu $(\bowtie)$

Dept. Math ematics, Hanshan Normal University, 521041, Chaozhou, China e-mail: ndwu@hstc.edu.cn

Items: Youth Project of Department of education of Guangdong Province ( No. 2012LYM_0096) Hanshan Normal University Start-up Project for Ph.D. (No. QD20091202)
} 


$$
d_{H}(A, B)=\operatorname{Max}\left\{\operatorname{Sup}_{a \in A} \inf _{b \in B} d(a, b), \operatorname{Sup}_{b \in B} \inf _{a \in A} d(a, b)\right\}
$$

for any $\mathrm{A}, \mathrm{B} \in \mathrm{Cld}(\mathrm{X})$.

Let $\Lambda \mathrm{L}=(\mathrm{L}, \lambda \mathrm{L}$ )be a Lawson semilattice $\mathrm{L}$ with the Lawson topology $\lambda \mathrm{L}$. Let $\downarrow$ USC $(X, L)$ denote all lower closed sets including $X \times\{0\}$ in the product space $\mathrm{X} \times \Lambda \mathrm{L}$ (a such set is called an upper-semi-continuous set). $\downarrow \mathrm{C}(\mathrm{X}, \mathrm{L})$ denotes all regions below of continuous maps from $\mathrm{X}$ to $\Lambda \mathrm{L}$. In what follows, $\downarrow$ $\mathrm{USC}(\mathrm{X}, \mathrm{L})$ and $\downarrow \mathrm{C}(\mathrm{X}, \mathrm{L})$ are considered as subspaces of Cld $(\mathrm{X} \times \Lambda \mathrm{L})$.

Pattern analysis and image management is one of practical undergrounds of the research on $\downarrow$ USC $(\mathrm{X}, \mathrm{L})$. In mathematical morphology which is one of the most important mathematical theories of pattern analysis and image management, 2-value image is thought to be a closed set of a fixed compact space which usually is a compact subspace of 3-dimensional Euclidean space and interval-value image a lower closed set of the product of the compact space and the unit interval. Hence $\downarrow$ USC(X, L) could be regarded as a mathematical model of all colored images.

For example, $\downarrow$ USC $\left(\mathrm{X}, \mathrm{I}^{3}\right)$ stands for the family of all three primary colored images. Moreover, the approach of images is just the Vietoris convergence of their mathematical Models (see [2], [3]). In fact, the topological structure of the family of all colored image is Hilbert cube (see [4, Theorem 1]).

A (single-valued) function $\mathrm{f}: \mathrm{X} \rightarrow \mathrm{R}$ is called upper semi-continuous if $\mathrm{f}^{-1}(-\infty$, $t$ ) is open in $X$ for every $t \in R$. For a Tychonoff space $X$ and $L \subset R$, let USC $(X, L)$ and $\mathrm{C}(\mathrm{X}, \mathrm{L})$ denote the family of all upper semi-continuous maps from $\mathrm{X}$ to $\mathrm{L}$ and the family of all continuous maps form $X$ to $L$ respectively .For every $f \in$ USC (X, I), let $\downarrow \mathrm{f}$ be the region below of $\mathrm{f}$, that is, $\downarrow \mathrm{f}=\{(\mathrm{x}, \lambda) \in \mathrm{X} \times \mathrm{I}: \lambda \leq \mathrm{f}(\mathrm{x})\}$ then $\downarrow \mathrm{f} \in \mathrm{Cld}(\mathrm{X} \times \mathrm{I})$. Hence $\downarrow$ USC $(\mathrm{X}, \mathrm{I})=\{\downarrow \mathrm{f}: \mathrm{f} \in \mathrm{USC}(\mathrm{X}, \mathrm{I})\}$ and $\downarrow \mathrm{C}(\mathrm{X}, \mathrm{I})=\{\downarrow \mathrm{f}: \mathrm{f} \in \mathrm{C}(\mathrm{X}, \mathrm{I})\}$. They are all subspaces of the hyperspace $\mathrm{Cld}(\mathrm{X}$ $X \mathrm{I})$. For convenience, let $\mathrm{USC}(\mathrm{X})=\mathrm{USC}(\mathrm{X}, \mathrm{I}), \mathrm{C}(\mathrm{X})=\mathrm{C}(\mathrm{X}, \mathrm{I})$. For any $\mathrm{A} \subset \mathrm{USC}(\mathrm{X})$, let $\downarrow \mathrm{A}=\{\downarrow f . f \in \mathrm{A}\}$. Let $\mathrm{USC}_{1}(\mathrm{X})=\mathrm{USC}(\mathrm{X}) \backslash \mathrm{USC}(\mathrm{X},[0,1))$. In this paper, we mainly research the topological structures of $\downarrow$ USC(X, $[0,1)$ ).

For two pairs of spaces $\left(X_{1}, Y_{1}\right)$ and $\left(X_{2}, Y_{2}\right)$ with $Y_{1} \subset X_{1}$ and $Y_{2} \subset X_{2}$, the symbol $\left(\mathrm{X}_{1}, \mathrm{Y}_{1}\right) \approx\left(\mathrm{X}_{2}, \mathrm{Y}_{2}\right)$ means that there exists a homeomorphism $\mathrm{h}: \mathrm{X}_{1} \rightarrow \mathrm{X}_{2}$ such that $h\left(\mathrm{Y}_{1}\right)=\mathrm{Y}_{2}$.

For a metric space $\mathrm{X}$, we use $\mathrm{X}_{0}$ and $\mathrm{cl}_{\mathrm{X}}(\cdot)$ to denote the set of all isolated points of $\mathrm{X}$ and the closure-operator in $\mathrm{X}$, respectively.

In [5], there was the following result.

Theorem 1. For a Tychonoff space $\mathrm{X}$, the following conditions are equivalent:

(a) $\mathrm{X}$ is a compactum and $\mathrm{cl}_{\mathrm{X}}\left(\mathrm{X}_{0}\right) \neq \mathrm{X}$;

(b) $\downarrow \mathrm{C}(\mathrm{X}, \mathrm{I}) \approx \mathrm{c}_{0}$;

(c) $(\downarrow \mathrm{USC}(\mathrm{X}, \mathrm{I}), \downarrow \mathrm{C}(\mathrm{X}, \mathrm{I})) \approx\left(\mathrm{Q}, \mathrm{c}_{0}\right)$

where $\mathrm{Q}=[-1,1] \infty$ is Hilbert cube and $c_{0}=\left\{x \in(-1,1)^{\infty}: \lim _{n \rightarrow \infty} x_{n}=0\right\}$ is a subspace of Q.

In the present paper we mainly prove the following results. 
Theorem 2. If $\mathrm{X}$ is an infinite compact metric space, then

$\left(\downarrow \operatorname{USC}(\mathrm{X}), \downarrow \mathrm{USC}_{1}(\mathrm{X})\right) \approx(\mathrm{I} \times \mathrm{Q}, \quad\{1\} \times \mathrm{Q})$.

It is well-known that $[0,1) \times \mathrm{Q} \approx \mathrm{Q} \backslash\{(0)\}$ (where $(0)=(0, \ldots, 0, \ldots) \in \mathrm{Q}$ ), hence we have the following corollary.

Corollary 1. For a compact metric space $\mathrm{X}$,

$$
\downarrow \operatorname{USC}(\mathrm{X},[0,1)) \approx\left\{\begin{array}{lc}
{[0,1)^{|\mathrm{X}|},} & \mathrm{X} \text { is finite } \\
\mathrm{Q} \backslash\{(0)\}, & \text { others }
\end{array},\right.
$$

where $|\mathrm{X}|$ denotes the cardinal of $\mathrm{X}$.

A closed subset $A$ of $X$ is said to be a $Z$-set of $X$ if the identity $i d_{X}$ can be approximated by continuous maps from $\mathrm{X}$ to $\mathrm{X} \backslash \mathrm{A}$.

The following theorem is due to [6, Theorem 5.4.12, Lemma 5.5.4, Lemma 5.5.12].

Theorem 3. If $\mathrm{A}$ is a $\mathrm{Z}$-set in $\mathrm{Q}$, then $\left(\mathrm{Q}, \mathrm{c}_{0} \backslash \mathrm{A}\right) \approx\left(\mathrm{Q}, \mathrm{c}_{0}\right)$.

Note that $\{1\} \times \mathrm{Q}$ is a Z-set of $\mathrm{I} \times \mathrm{Q}$. Hence by Theorems 1,2 and 3 , there is the following Corollary.

Corollary 2. If $\mathrm{X}$ is a compact metric space with $\mathrm{cl}_{\mathrm{X}}\left(\mathrm{X}_{0}\right) \neq \mathrm{X}$, then

$\downarrow \mathrm{C}(\mathrm{X},[0,1)) \approx \mathrm{c}_{0}$

\subsection{Preliminaries}

All spaces under discussion are assumed to be separable and metrizable spaces.

If $\mathrm{X}$ is a metric space, we can give another equivalent definition for upper semicontinuous map.

Definition 1. A map f: $\mathrm{X} \rightarrow \mathrm{R}$ is called a upper semi-continuous, if for every $\mathrm{x}_{0} \in$ $\mathrm{X}$ and $\varepsilon>0$, there exists $\delta>0$, such that for every $\mathrm{x} \in \mathrm{U}\left(\mathrm{x}_{0}, \delta\right), \mathrm{f}\left(\mathrm{x}_{0}\right)>\mathrm{f}(\mathrm{x})-\varepsilon$.

Definition 2. A space $\mathrm{X}$ is called an absolute retract, abbreviated AR, provided that for every space $\mathrm{Y}$ containing $\mathrm{X}$ as a closed subspace, $\mathrm{X}$ is a retract of $\mathrm{Y}$, that is, there exists a continuous map $r: Y \rightarrow X$ such that $\left.r\right|_{X}=i d_{X}$.

Definition 3. A subset A of a space $\mathrm{Y}$ is called homotopy dense in $\mathrm{Y}$ if there exists a homotopy $h: Y \times I \rightarrow Y$ such that $h_{0}=i_{\mathrm{Y}}$ and $h_{t}(Y) \subset A$ for every $\mathrm{t}>0$.

Definition 4. A topological semilattice is a topological space $S$ equipped with a continuous operator $V: S \times S \rightarrow S$ which is idempotent, commutative and associative (i.e., $\mathrm{x} \vee \mathrm{x}=\mathrm{x}, \mathrm{x} \vee \mathrm{y}=\mathrm{y} \vee \mathrm{x} ;(\mathrm{x} \vee \mathrm{y}) \vee \mathrm{z}=\mathrm{x} \vee(\mathrm{y} \vee \mathrm{z})$ for any $\mathrm{x}, \mathrm{y}, \mathrm{z} \in$ $S)$. A topological semilattice $S$ is called a Lawson semilattice if $S$ admits an open basis consisting of subsemilattices. 
Definition 5. Let $X$ be a space. A subset $Y \subset X$ is relatively $L^{0}$ in $X$ if for every $\mathrm{x} \in \mathrm{X}$, each neighborhood $\mathrm{U}$ of $\mathrm{x}$ in $\mathrm{X}$ contains a smaller neighborhood $\mathrm{V}$ of $\mathrm{X}$ such that every two points of $\mathrm{V} \cap \mathrm{Y}$ can be joined by a path in $\mathrm{U} \cap \mathrm{Y}$.

Lemma 1. ([7, Theorem 5.1]) Let $X$ be a metrizable Lawson semilattice with $\mathrm{Y} \subset \mathrm{X}$ a dense subsemilattice. If $\mathrm{Y}$ is relatively $\mathrm{LC}^{0}$ in $\mathrm{X}$ and path-connected, then $\mathrm{X}$ is an $\mathrm{AR}$ and $\mathrm{Y}$ is homotopy dense in $\mathrm{X}$, hence $\mathrm{Y}$ is also an AR.

Definition 6. We say a space (X, d) has the disjoint-cells property, if for any $\varepsilon>$ $0, \mathrm{k} \in \mathrm{N}$ and continuous functions $\mathrm{f}, \mathrm{g}: \mathrm{I}^{\mathrm{k}} \rightarrow \mathrm{X}$, there exist continuous functions $\mathrm{f}_{1}$, g such that $\mathrm{d}\left(\mathrm{f}_{1}, \mathrm{f}\right)<\varepsilon$, d $\left(\mathrm{g}_{1}, \mathrm{~g}\right)<\varepsilon$ and $\mathrm{f}_{1}\left(\mathrm{I}^{\mathrm{k}}\right) \cap \mathrm{g}_{1}\left(\mathrm{I}^{\mathrm{k}}\right)=\varnothing$.

Lemma 2. (The Toru'nczyk's Characterization Theorem ) [8] (cf. [9, Corollary 7.8.4] ) : A space $X$ is homeomorphic to the Hilbert cube $Q$ if and only if it is a compact AR with the disjoint-cells property.

The above lemma is a key to prove Theorem 2 .

Lemma 3. [9, Theorem 6.4.6]Let $\mathrm{E}, \mathrm{F}$ be Z-sets of $\mathrm{Q}, \varepsilon>0$, and $\mathrm{h}: \mathrm{E} \rightarrow \mathrm{F}$ be a homeomorphism such that $\hat{\rho}(\mathrm{x}, \mathrm{h}(\mathrm{x}))<\varepsilon$ for every $\mathrm{x} \in \mathrm{E}$. Then there exists a homeomorphism $\mathrm{H}: \mathrm{Q} \rightarrow \mathrm{Q}$, such that $\left.\mathrm{H}\right|_{\mathrm{E}}=\mathrm{h}$ and $\hat{\rho}(\mathrm{x}, \mathrm{H}(\mathrm{x}))<\varepsilon$ for every $\mathrm{x} \in \mathrm{Q}$.

Let $\phi: \mathrm{A} \rightarrow \mathrm{B}$ be a map from a set $\mathrm{A}$ to a set $\mathrm{B}$. If $\mathrm{A} \subset \mathrm{USC}(\mathrm{X})$ and/or $\mathrm{B} \subset \mathrm{USC}(\mathrm{Y})$ for spaces $\mathrm{X}$ and $\mathrm{Y}$, we may define a corresponding map $\downarrow \phi: \downarrow \mathrm{A}$ $\rightarrow \downarrow \mathrm{B}$ or $\downarrow \phi: \mathrm{A} \rightarrow \downarrow \mathrm{B}$ or $\downarrow \phi: \downarrow \mathrm{A} \rightarrow \mathrm{B}$ as $\downarrow \phi(\downarrow f)=\downarrow(\phi(f))$ or $\downarrow \phi$ $(f)=\downarrow(\phi(f))$ or $\downarrow \phi(\downarrow f)=\phi(f)$, respectively.

\subsection{Proof of theorem 2}

In follows, we always consider that $\hat{\rho}$ is the metric of the metric space $\mathrm{I} \times \mathrm{Q}$, where $\hat{\rho}(\mathrm{x}, \mathrm{y})=\sqrt{\sum_{\mathrm{i}=0}^{\infty} \frac{\left|\mathrm{x}_{\mathrm{i}}-\mathrm{y}_{\mathrm{i}}\right|^{2}}{2^{\mathrm{i}}}}$ for every $\left.\left.\mathrm{x}=\mathrm{x}_{\mathrm{i}}\right)_{\mathrm{i} \in \mathrm{N}}, \mathrm{y}=\mathrm{y}_{\mathrm{i}}\right)_{\mathrm{i} \in \mathrm{N}} \in \mathrm{I} \times \mathrm{Q}$.

Lemma 4. $\{1\} \times Q$ is a Z-set in $I \times Q$.

Proof. It is easy to check.

Lemma 5. Let $A$ be a space of $I \times Q$, then $(I \times Q, A) \approx(I \times Q,\{1\} \times Q)$ if and only if A is a copy of $\mathrm{Q}$ and a Z-set of $\mathrm{I} \times \mathrm{Q}$.

Proof. The essentiality is trivial. The sufficiency follows form lemmas 3 and 4 .

In this section we always assume that $\mathrm{X}$ is an infinite compact space and $\rho$ is an admissible metric of $\mathrm{X}$. $\mathrm{d}$ is the metric on $\mathrm{X} \times \mathrm{I}$ defined by

$$
\mathrm{d}\left(\left(\mathrm{x}_{1}, \mathrm{t}_{1}\right),\left(\mathrm{x}_{2}, \mathrm{t}_{2}\right)\right)=\max \left\{\rho\left(\mathrm{x}_{1}, \mathrm{x}_{2}\right), \quad\left|\mathrm{t}_{1}-\mathrm{t}_{2}\right|\right\} .
$$

Lemma 6. $\downarrow$ USC $_{1}(\mathrm{X})$ is closed in $\downarrow$ USC (X).

Proof. Let $\left\{\mathrm{f}_{\mathrm{n}}\right\}$ be a sequence in $\mathrm{USC}_{1}(\mathrm{X})$ and $\downarrow \mathrm{f}_{\mathrm{n}} \rightarrow \downarrow \mathrm{f}(\mathrm{n} \rightarrow \infty)$. It suffices to prove that $f \in U^{\prime} C_{1}(X)$. For every $n \in N$, there exists $x_{n} \in X$ such that 
$f_{n}\left(x_{n}\right)=1$ since $f_{n} \in \operatorname{USC}_{1}(X)$. By the compactness of $X,\left\{x_{n}\right\}$ has a convergence subsequence $\left\{x_{n k}\right\}$. Assume $x_{n k} \rightarrow y, k \rightarrow \infty$, then $\left(x_{n k}, 1\right) \rightarrow(y, 1)(k \rightarrow \infty)$. It follows from $\left(\mathrm{x}_{\mathrm{nk}}, 1\right) \in \downarrow \mathrm{f}_{\mathrm{nk}}$ and $\downarrow \mathrm{f}_{\mathrm{nk}} \rightarrow \downarrow \mathrm{f}(\mathrm{k} \rightarrow \infty)$ that $(\mathrm{y}, 1) \in \downarrow \mathrm{f}$. That is $f(y)=1$. We are done.

Lemma 7. $\downarrow$ USC $_{1}(\mathrm{X})$ is a Z-set of $\downarrow$ USC (X).

Proof. For every $\varepsilon>0$, pick $\mathrm{y} \in(1-\varepsilon, 1)$. Define $\alpha: \mathrm{I} \rightarrow[0, \mathrm{y}]$ by $\alpha(\mathrm{t})=\mathrm{yt}$ for every $\mathrm{t} \in \mathrm{I}$. Define $\mathrm{H}: \mathrm{USC}(\mathrm{X}) \rightarrow \mathrm{USC}(\mathrm{X},[0, \mathrm{y}])$ by $\mathrm{H}(\mathrm{f}(\mathrm{x}))=\alpha \mathrm{f}(\mathrm{x})$ for every $\mathrm{f} \in \mathrm{USC}(\mathrm{X})$ and $\mathrm{x} \in \mathrm{X}$. It is trivial that $\downarrow \mathrm{H}$ is continuous and $\mathrm{d}_{\mathrm{H}}(\downarrow \mathrm{H}(\mathrm{f}), \downarrow \mathrm{f})<\varepsilon$. Hence Lemma 7 holds by Lemma 6 .

Lemma 8. $\downarrow \mathrm{C}_{1}(\mathrm{X})$ is dense in $\downarrow \mathrm{USC}_{1}(\mathrm{X})$.

Proof. For every $\varepsilon>0$ and $\mathrm{f} \in \downarrow \mathrm{USC}_{1}(\mathrm{X})$, it suffices to prove that there exists $\mathrm{g} \in \mathrm{C}_{1}(\mathrm{X})$ such that $\mathrm{d}_{\mathrm{H}}(\downarrow \mathrm{g}, \downarrow \mathrm{f})<\varepsilon$. Since $\mathrm{X}$ is compact, there exists $\left\{\mathrm{x}_{1}, \mathrm{x}_{2}, \cdots, \mathrm{x}_{\mathrm{n}}\right\} \subset \mathrm{X}$ such that $\left\{\mathrm{U}\left(\mathrm{x}_{\mathrm{i}}, \frac{\varepsilon}{2}\right) \mid \mathrm{i}=1,2, \ldots, \mathrm{n}\right\}$ covers $\mathrm{X}$ and none of $\mathrm{U}\left(\mathrm{x}_{\mathrm{i}}, \frac{\varepsilon}{2}\right)$ could be covered by other balls.

Let $\delta=0.5 \times \min \left\{\varepsilon, \min \left\{\mathrm{d}\left(\mathrm{x}_{\mathrm{i}}, \mathrm{x}_{\mathrm{j}}\right) \mid \mathrm{i} \neq \mathrm{j}, \mathrm{i}, \mathrm{j} \in\{1,2, \ldots, \mathrm{n}\}\right\}\right\}$, then $\delta>0$. Let $\mathrm{g}\left(\mathrm{x}_{\mathrm{i}}\right)=\operatorname{Sup}\left\{\mathrm{f}(\mathrm{x}) \mid \mathrm{x} \in \mathrm{U}\left(\mathrm{x}_{\mathrm{i}}, \varepsilon / 2\right)\right\}, \mathrm{g}(\mathrm{x})=0$ for every $\mathrm{x} \in \mathrm{X} \backslash \bigcup_{\mathrm{i}=1}^{\mathrm{n}} \mathrm{U}\left(\mathrm{x}_{\mathrm{i}}, \delta\right)$. If $\mathrm{x} \in \bigcup_{\mathrm{i}=1}^{\mathrm{n}} \mathrm{U}\left(\mathrm{x}_{\mathrm{i}}, \delta\right)$, it follows from the definition of $\delta$ that there exists only one $\mathrm{i} \in\{1$, $2, \ldots, \mathrm{n}\}$ such that $\mathrm{x} \in \mathrm{U}\left(\mathrm{x}_{\mathrm{i}}, \delta\right)$. Thus we can define $\mathrm{g}(\mathrm{x})=\left(1-\mathrm{d}\left(\mathrm{x}, \mathrm{x}_{\mathrm{i}}\right) / \delta\right) \mathrm{g}\left(\mathrm{x}_{\mathrm{i}}\right)$. It is trivial that $\mathrm{g}(\mathrm{x}) \in \mathrm{C}_{1}(\mathrm{X})$ and we only need to show the following fact.

Fact. $\mathrm{d}_{\mathrm{H}}(\downarrow \mathrm{f}, \downarrow \mathrm{g})<\varepsilon$.

On one hand, for every $(x, t) \in \downarrow$ f. There exists $i \in\{1,2, \ldots, n\}$ such that $\mathrm{x} \in \mathrm{U}\left(\mathrm{x}_{\mathrm{i}}, \varepsilon / 2\right)$. Since $\mathrm{g}\left(\mathrm{x}_{\mathrm{i}}\right)=\sup \left\{\mathrm{f}(\mathrm{x}) \mid \mathrm{x} \in \mathrm{U}\left(\mathrm{x}_{\mathrm{i}}, \varepsilon / 2\right)\right\},\left(\mathrm{x}_{\mathrm{i}}, \mathrm{t}\right) \in \downarrow \mathrm{g}$. Noting that $\mathrm{d}\left((\mathrm{x}, \mathrm{t}),\left(\mathrm{x}_{\mathrm{i}}, \mathrm{t}\right)\right)=\rho\left(\mathrm{x}, \mathrm{x}_{\mathrm{i}}\right)<\varepsilon / 2$. We conclude that $\downarrow \mathrm{f} \in \mathrm{B}_{\mathrm{d}}(\downarrow \mathrm{g}, \varepsilon / 2)$. On the other hand, for every $(\mathrm{x}, \lambda) \in \downarrow$ g, there exists $\mathrm{i} \in\{1,2, \ldots, \mathrm{n}\}$ such that $\mathrm{x} \in \mathrm{U}\left(\mathrm{x}_{\mathrm{i}}\right.$, $\varepsilon / 2)$ and then $\left(\mathrm{x}_{\mathrm{i}}, \lambda\right) \in \downarrow \mathrm{g}$ by the definition of $\mathrm{g}$. Since $\mathrm{g}\left(\mathrm{x}_{\mathrm{i}}\right)=\operatorname{Sup}\left\{\mathrm{f}(\mathrm{x}) \mid \mathrm{x} \in \mathrm{U}\left(\mathrm{x}_{\mathrm{i}}\right.\right.$, $\varepsilon / 2)\}$, there exists $\mathrm{y} \in \mathrm{U}\left(\mathrm{x}_{\mathrm{i}}, \varepsilon / 2\right)$ such that $\mathrm{g}\left(\mathrm{x}_{\mathrm{i}}\right)-\mathrm{f}(\mathrm{y})<\varepsilon / 2$. If $\mathrm{g}\left(\mathrm{x}_{\mathrm{i}}\right) \geq \lambda>\mathrm{f}(\mathrm{y})$, then $\lambda$-f(y)< $\varepsilon / 2$, and hence $\mathrm{d}((\mathrm{x}, \lambda),(\mathrm{y}, \mathrm{f}(\mathrm{y}))) \leq \mathrm{d}\left((\mathrm{x}, \lambda),\left(\mathrm{x}_{\mathrm{i}}, \lambda\right)\right)+\mathrm{d}\left(\left(\mathrm{x}_{\mathrm{i}}, \lambda\right)\right.$, $(\mathrm{y}, \mathrm{f}(\mathrm{y})))=\rho\left(\mathrm{x}, \mathrm{x}_{\mathrm{i}}\right)+\min \left\{\rho\left(\mathrm{x}_{\mathrm{i}}, \mathrm{y}\right), \lambda-\mathrm{f}(\mathrm{y})\right\}<\varepsilon / 2+\varepsilon / 2=\varepsilon$. If $\lambda<\mathrm{f}(\mathrm{y})$, then $(\mathrm{y}, \lambda) \in \downarrow \mathrm{f}$ and $\mathrm{d}((\mathrm{x}, \lambda),(\mathrm{y}, \lambda))=\rho(\mathrm{x}, \mathrm{y}) \leq \rho\left(\mathrm{x}, \mathrm{x}_{\mathrm{i}}\right)+\rho\left(\mathrm{y}, \mathrm{x}_{\mathrm{i}}\right)<$ $\varepsilon / 2+\varepsilon / 2=\varepsilon$. Thus $\downarrow \mathrm{g} \in \mathrm{B}_{\mathrm{d}}(\downarrow \mathrm{f}, \varepsilon)$. That is $\mathrm{d}_{\mathrm{H}}(\downarrow \mathrm{f}, \downarrow \mathrm{g})<\varepsilon$.

Lemma 9. $\downarrow \mathrm{USC}_{1}(\mathrm{X})$ is AR and $\downarrow \mathrm{C}_{1}(\mathrm{X})$ is homotopy dense in $\downarrow \mathrm{USC}_{1}(\mathrm{X})$.

Proof. Define $\vee: \downarrow$ USC $_{1}(\mathrm{X}) \times \downarrow \mathrm{USC}_{1}(\mathrm{X}) \rightarrow \downarrow \mathrm{USC}_{1}(\mathrm{X})$ by $\downarrow \mathrm{f} \vee \downarrow \mathrm{g}$ $=\downarrow \max \{\mathrm{f}(\mathrm{x}), \mathrm{g}(\mathrm{x})\}=\downarrow \mathrm{f} \vee \downarrow \mathrm{g}$, then $\vee$ is continuous.

Claim 1. ( $\downarrow \mathrm{USC}_{1}(\mathrm{X}), \vee$ ) is a semi-lattice. 
It suffices to prove that $\downarrow \mathrm{g} \vee \downarrow \mathrm{h} \in \mathrm{B}_{\mathrm{d}_{\mathrm{H}}}$ ( $\left.\downarrow \mathrm{f}, \varepsilon\right)$ for any $\downarrow \mathrm{g}$, $\downarrow$ $\mathrm{h} \in \mathrm{B}_{\mathrm{d}_{\mathrm{H}}}(\downarrow \mathrm{f}, \varepsilon)$, where $\mathrm{B}_{\mathrm{d}_{\mathrm{H}}}(\downarrow \mathrm{f}, \varepsilon)=\left\{\downarrow \mathrm{f} \in \downarrow \mathrm{USC}(\mathrm{X}) \mid \mathrm{d}_{\mathrm{H}}(\downarrow \mathrm{f}, \downarrow \mathrm{g})<\varepsilon\right\}$. On one hand, for any point $\mathrm{p} \in \downarrow \mathrm{f}$, since $\mathrm{d}_{\mathrm{H}}(\downarrow \mathrm{f}, \downarrow \mathrm{g})<\varepsilon$, there exists $\mathrm{p}_{0} \in \downarrow \mathrm{g} \subset$ $\downarrow \mathrm{g} \vee \downarrow$ h such that $\mathrm{d}\left(\mathrm{p}, \mathrm{p}_{0}\right)<\varepsilon$. On the other hand, if the point $\mathrm{q} \in \downarrow \mathrm{g} \vee \downarrow \mathrm{h}$, then $\mathrm{q} \in \downarrow$ g or $\mathrm{q} \in \downarrow$ h. Since $\downarrow \mathrm{g}, \downarrow \mathrm{h} \in \mathrm{B}_{\mathrm{d}_{\mathrm{H}}}(\downarrow \mathrm{f}, \varepsilon)$, there exists $\mathrm{q}_{0} \in \downarrow \mathrm{f}$ such that $\mathrm{d}\left(\mathrm{q}, \mathrm{q}_{0}\right)<\varepsilon$. Thus $\downarrow \mathrm{g} \vee \downarrow \mathrm{h} \in \mathrm{B}_{\mathrm{d}_{\mathrm{H}}}(\downarrow \mathrm{f}, \varepsilon)$.

Claim 2. $\downarrow \mathrm{C}_{1}(\mathrm{X})$ is a sub semi-lattice of $\downarrow \mathrm{USC}_{1}(\mathrm{X})$.

For any $\downarrow g_{1}, \downarrow g_{2} \in \downarrow C_{1}(X)$, if $\downarrow g=\downarrow g_{1} \vee \downarrow g_{2}$, it is easy to check that $\mathrm{g} \in \mathrm{C}_{1}(\mathrm{X})$. Thus by Claim $1, \downarrow \mathrm{C}_{1}(\mathrm{X})$ is a sub semi-lattice of $\downarrow \mathrm{USC}_{1}(\mathrm{X})$.

Claim 3. $\downarrow \mathrm{C}_{1}(\mathrm{X})$ is relatively $\mathrm{LC}^{0}$ in $\downarrow \mathrm{USC}_{1}(\mathrm{X})$ and path connected.

For any $\downarrow \mathrm{f} \in \downarrow \mathrm{USC}_{1}(\mathrm{X})$ and $\varepsilon>0$, we shall prove that $\downarrow \mathrm{U}=\mathrm{B}_{\mathrm{d}_{\mathrm{H}}}(\downarrow \mathrm{f}, \varepsilon) \cap$

$\downarrow \mathrm{C}_{1}(\mathrm{X})$ is path connected. For any $\downarrow \mathrm{g}_{1}, \downarrow \mathrm{g}_{2} \in \downarrow \mathrm{U}, \downarrow \mathrm{g}=\downarrow \mathrm{g}_{1} \vee \downarrow \mathrm{g}_{2} \in \downarrow \mathrm{U}$ by Claim 1. Define $\downarrow \mathrm{H}: \mathrm{I} \rightarrow \downarrow$ U by H(t)=(1-t) $\mathrm{g}_{1}+\mathrm{tg}$, then $\downarrow \mathrm{H}$ is well defined and a path from $\downarrow g_{1}$ to $\downarrow$ g (cf. proof of [5, Lemma 6]). Similarly, there exists a path joining $\downarrow \mathrm{g}$ and $\downarrow \mathrm{g}_{2}$ in $\downarrow \mathrm{U}$. We conclude that $\downarrow \mathrm{C}_{1}(\mathrm{X})$ is relatively LC $\mathrm{LC}^{0}$. Similarly, it can be proved that $\downarrow \mathrm{C}_{1}(\mathrm{X})$ is path connected.

It follows from the above claims, Lemmas 1 and 8 that Lemma 9 holds. We are done.

Lemma 10. $\downarrow \mathrm{USC}_{1}(\mathrm{X})$ has disjoint-cells property.

Proof. For every $\mathrm{n} \in \mathrm{N}$, let $\phi: \mathrm{I}^{n} \rightarrow \downarrow \mathrm{USC}_{1}(\mathrm{X})$ and $\varphi: \mathrm{I}^{n} \rightarrow \downarrow \mathrm{USC}_{1}(\mathrm{X})$ are two continuous maps. By Lemma 9, there exists a homeotopy H: $\downarrow \operatorname{USC}_{1}(\mathrm{X}) \times \mathrm{I} \rightarrow \downarrow$ $\mathrm{USC}_{1}(\mathrm{X})$ such that $\mathrm{H}_{0}=\mathrm{id}, \mathrm{H}_{\mathrm{t}}\left(\downarrow \mathrm{USC}_{1}(\mathrm{X})\right) \subset \downarrow \mathrm{C}_{1}(\mathrm{X})$ for every $\mathrm{t} \in(0,1]$. For every $1>\varepsilon>0$, let $\Phi, \Psi: \mathrm{I}^{n} \rightarrow \downarrow \mathrm{USC}_{1}(\mathrm{X})$ be two maps defined by $\Phi(\mathrm{m})=\mathrm{H}(\phi(\mathrm{m})$, $\varepsilon / 2)$ and $\Psi(\mathrm{m})=\mathrm{H}(\varphi(\mathrm{m}), \varepsilon / 2)$ for every $\mathrm{m} \in \mathrm{I}^{n}$, respectively. Choose a nonisolated point $\mathrm{x}_{0} \in \mathrm{X}$ arbitrarily and a point $\mathrm{x}_{1} \in \mathrm{U}^{0}\left(\mathrm{x}_{0}, \varepsilon / 3\right)$. Let the map M: $\downarrow \mathrm{C}_{1}(\mathrm{X}) \rightarrow \mathrm{I}$ defined by $\left.\mathrm{M}(\downarrow \mathrm{f})=\max \left\{\mathrm{f}(\mathrm{x}): \mathrm{d}\left(\mathrm{x}_{0}, \mathrm{x}\right)\right\} \leq \varepsilon\right\}$. Then $\mathrm{M}$ is continuous by [10, Lemma 14]. Let $S: \downarrow C_{1}(X) \rightarrow$ I defined by $S(\downarrow f)=\max \{\varepsilon, M(\downarrow f)\}$. It is trivial that $S$ is continuous. Define two maps $\downarrow a, \downarrow \beta: \downarrow C_{1}(X) \rightarrow \downarrow$ USC $_{1}(X)$ $\begin{aligned} \text { by a }(f)(x) & =\left\{\begin{array}{cc}S(\downarrow f), & x=x_{0} \\ 0, & x \in U^{0}\left(x_{0}, \varepsilon / 2\right)\end{array} \text { and }\right. \\ f(x), & \text { others } \\ \beta(f)(x) & =\left\{\begin{array}{cc}S(\downarrow f), & x=x_{1} \\ 0, & x \in U\left(x_{0}, \varepsilon / 2\right) \backslash\left\{x_{1}\right\} \\ \mathrm{f}(\mathrm{x}), & \text { others }\end{array} \text { for every } \downarrow f \in \downarrow \mathrm{C}_{1}(\mathrm{X}) \text { and } \mathrm{x} \in \mathrm{X} .\right.\end{aligned}$

Claim 1. $\downarrow \alpha, \downarrow \beta$ are well-defined and continuous. 
It is easy to check that $\downarrow$ a (f) and $\downarrow \beta$ (f) are upper semi-continuous for every $\mathrm{f} \in \mathrm{C}_{1}(\mathrm{X})$. For every $\mathrm{f} \in \mathrm{C}_{1}(\mathrm{X})$, there exists $\mathrm{y} \in \mathrm{X}$ such that $\mathrm{f}(\mathrm{y})=1$. If $\mathrm{y} \in \mathrm{U}\left(\mathrm{x}_{0}, \varepsilon / 2\right)$, then a $(\mathrm{f})\left(\mathrm{x}_{0}\right)=a(\mathrm{f})\left(\mathrm{x}_{1}\right)=1$; if $\mathrm{y} \in \mathrm{X} \backslash \mathrm{U}\left(\mathrm{x}_{0}, \varepsilon / 2\right)$, then $a$ (f)(y) $=\beta$ (f)(y) $=\mathrm{f}(\mathrm{y})=1$. Thus, $\downarrow$ a,$\downarrow \beta$ are $\quad$ well-defined. For every $\downarrow \mathrm{f} \in \downarrow$ $\mathrm{C}_{1}(\mathrm{X})$ and every $\gamma>0$, we shall prove that there exists $\tau>0$, such that if $\mathrm{d}_{\mathrm{H}}(\downarrow \mathrm{f}$, $\downarrow$ g) $<\tau$, then $\mid \downarrow$ a (f ) $-\downarrow$ a (g) $\mid<\gamma$. By the continuity of S, there exists $\tau_{1}>0$, such that if $d_{H}(\downarrow f, \downarrow g)<\tau_{1}$, then $|S(\downarrow f)-S(\downarrow g)|<\gamma$. Since $X$ is compact and $\mathrm{f}$ $\in \mathrm{C}_{1}(\mathrm{X})$, $\mathrm{f}$ is uniformly continuous on $\mathrm{X}$, that is, there exits $\tau_{2}>0$ such that $\mid \mathrm{f}(\mathrm{x})$ $\mathrm{f}(\mathrm{y}) \mid<\gamma / 2$ for every $\mathrm{x}, \mathrm{y} \in \mathrm{X}$ with $\rho(\mathrm{x}, \mathrm{y})<\tau_{2}$. Choose $\tau=\min \left\{\gamma / 2, \tau_{1}, \tau_{2}\right\}$, it suffices to prove that $\mathrm{d}_{\mathrm{H}}$ ( $\downarrow$ a (f), $\downarrow$ a (g)) $<\gamma$ for every $\downarrow \mathrm{g} \in \downarrow \mathrm{C}_{1}(\mathrm{X})$ with $\mathrm{d}_{\mathrm{H}}(\downarrow \mathrm{f}, \downarrow \mathrm{g})<\tau$.

On one hand, for every (x, $\lambda) \in \downarrow a$ (g), we shall find a point (y, z) $\in \downarrow$ a (f) such that $\mathrm{d}((\mathrm{x}, \lambda),(\mathrm{y}, \mathrm{z}))<\gamma$. Consider three cases.

Case 1. If $\mathrm{x}=\mathrm{x}_{0}$, then it follows from the continuity of the map $\mathrm{S}$.

Case 2. If $\mathrm{x} \in \mathrm{U}^{0}\left(\mathrm{x}_{0}, \varepsilon / 2\right)$, then $(\mathrm{x}, \lambda)=(\mathrm{x}, 0) \in \downarrow a(\mathrm{f})$. Choose $(\mathrm{y}, \mathrm{z})=(\mathrm{x}, 0)$ as required.

Case 3. If $\mathrm{x} \in \mathrm{X} \backslash \mathrm{U}\left(\mathrm{x}_{0}, \varepsilon / 2\right)$, then $(\mathrm{x}, \lambda) \in \downarrow \mathrm{g}$, there exists $\left(\mathrm{x}^{\prime}, \lambda^{\prime}\right) \in \downarrow \mathrm{f}$ such that $\mathrm{d}\left((\mathrm{x}, \lambda),\left(\mathrm{x}^{\prime}, \lambda^{\prime}\right)\right)<\tau$. If $\mathrm{x}^{\prime} \in \mathrm{X} \backslash \mathrm{U}\left(\mathrm{x}_{0}, \varepsilon / 2\right)$, then $\left(\mathrm{x}^{\prime}, \lambda^{\prime}\right) \in \downarrow$ a (f). We can just choose $(\mathrm{y}, \mathrm{z})=\left(\mathrm{x}^{\prime}, \lambda^{\prime}\right)$ as required. If $\mathrm{x}^{\prime} \in \mathrm{U}\left(\mathrm{x}_{0}, \varepsilon / 2\right)$, then $\mid \mathrm{f}(\mathrm{x})$ $\mathrm{f}\left(\mathrm{x}^{\prime}\right) \mid<\gamma / 2$ since $\mathrm{d}\left(\mathrm{x}, \mathrm{x}^{\prime}\right)<\tau<\tau_{2}$. Hence there exists $\lambda_{1}$ such that $\mid \lambda_{1}$ $\lambda^{\prime} \mid<\gamma / 2$ and $\left(\mathrm{x}, \lambda_{1}\right) \in \downarrow \mathrm{f}$. Thus $\left|\lambda-\lambda^{\prime}\right| \leq\left|\lambda-\lambda^{\prime}\right|+\left|\lambda_{1}-\lambda^{\prime}\right|<\tau+\gamma / 2 \leq \gamma$, hence $d\left((x, \lambda),\left(x, \lambda_{1}\right)\right)<\gamma$. Choose $(y, z)=\left(x, \lambda_{1}\right)$, then $(y, z)$ is as required.

Therefore, $\downarrow$ a (g) $\subset \mathrm{B}_{\mathrm{d}}(\downarrow$ a (f), $\gamma$ ).

On the other hand, we can proved that $\downarrow$ a (f) $\subset \mathrm{B}_{\mathrm{d}}(\downarrow a$ (g), $\gamma$ ) similarly. Thus $\mathrm{d}_{\mathrm{H}}(\downarrow$ a (f), $\downarrow$ a (g) $)<\gamma$. That is, $\downarrow \alpha$ is continuous. It is a similar proof for the continuity of $\downarrow \beta$.

Put $\phi^{\prime}: \mathrm{I}^{n} \rightarrow \downarrow \mathrm{USC}_{1}(\mathrm{X})$ and $\varphi^{\prime}: \mathrm{I}^{n} \rightarrow \downarrow \mathrm{USC}_{1}(\mathrm{X})$ by $\phi^{\prime}=\downarrow \alpha \circ \Phi$ and $\varphi^{\prime}=$ $\downarrow \beta \circ \Psi$. It is easy to see that $\phi^{\prime}\left(\downarrow \operatorname{USC}_{1}(\mathrm{X})\right) \cap \varphi^{\prime}\left(\downarrow \operatorname{USC}_{1}(\mathrm{X})\right)=\emptyset$. Thus, it suffices to prove the following claims.

Claim 2. $\phi^{\prime}$ and $\varphi^{\prime}$ are continuous.

It follows from the continuity of the maps $\downarrow \alpha, \downarrow \beta, \Phi$ and $\Psi$.

Claim 3. $\mathrm{d}_{\mathrm{H}}\left(\varphi(\mathrm{m}), \varphi^{\prime}(\mathrm{m})\right)<\varepsilon$ and $\mathrm{d}_{\mathrm{H}}\left(\phi(\mathrm{m}), \phi^{\prime}(\mathrm{m})\right)<\varepsilon$ for every $\mathrm{m} \in \mathrm{I}^{n}$.

By [6, Propositi on 4.1.7], without loss of generliy, we can assume that $\mathrm{d}_{\mathrm{H}}(\phi(\mathrm{m}), \Phi(\mathrm{m}))=\mathrm{d}_{\mathrm{H}}(\phi(\mathrm{m}), \mathrm{H}(\phi(\mathrm{m}), \varepsilon / 2))<\varepsilon / 2$ and $\mathrm{d}_{\mathrm{H}}(\varphi(\mathrm{m}), \Psi(\mathrm{m}))=\mathrm{d}_{\mathrm{H}}$ 
( $\varphi(\mathrm{m}), \mathrm{H}(\varphi(\mathrm{m}), \varepsilon / 2))<\varepsilon / 2$. It is trival that $\mathrm{d}_{\mathrm{H}}(\phi(\mathrm{m}), \Phi(\mathrm{m}))<\varepsilon / 2$ and $\mathrm{d}_{\mathrm{H}}(\Psi$ $\left.(\mathrm{m}), \varphi^{\prime}(\mathrm{m})\right)<\varepsilon / 2$. Thus $\mathrm{d}_{\mathrm{H}}\left(\varphi(\mathrm{m}), \varphi^{\prime}(\mathrm{m})\right)<\varepsilon$ and $\mathrm{d}_{\mathrm{H}}\left(\phi(\mathrm{m}), \phi^{\prime}(\mathrm{m})\right)<\varepsilon$.

Proof of Theorem 2. It follows from Lemmas 2, 6, 9 and 10 that $\downarrow$ USC $_{1}(\mathrm{X}) \approx \mathrm{Q}$. By Lemmas 5 and 7, we conclude that Theorem 2 holds.

\subsection{References}

1. Illanes A, Nadler S (1999) Hyperspaces, Fundamental and Recent Advances. Pure and Applied Mat. 216, Marcel Dekker, Inc., New York

2. Serra J (1986) Introduction of mathematical morphology. Comput. Vision Graphics Image Process 35(2):283- 305

3. Serra J (1982) Image Analysis and Mathematical Morphology. Academic Press, London

4. Yang Z (2005) The hyperspace of the regions below of all lattice-value continuous maps and its Hilbert cube compactification. Science in. China Ser. A Mathematics. 148: 469-184

5. Yang Z, Zhou X (2007) A pair of spaces of upper semi-continuous maps and continuous maps. Topology Appl. 154:1737-1747

6. Van Mll J (2001) The In fin it e-D nensional Topol ogy of Funct i on Spaces. No th- Hl land Mt h. Li brary, vol. 64, El sevi er Sci. Publ. B. V., Anst er dam

7. Kubi W, Sakai K, Yaguchi M (2005) Hyperspaces of separable Banach spaces with the Wijsman topology. Topoloy Appl. 148: 7-32

8. Torun'czyk H (1980) On CE-images of the Hilbert cube and characterizations of Q-manifolds. Fund. Math. 106, 431-437.

9. Van Mll J (1989) Infinite-Dimensional Topology, Prerequisites and Introduction. NorthHolland Math. Library 43, Elsevier Sci. Publ. B.V., Amsterdam

10. Yang $Z$ (2006) The hyperspace of the regions below of all continuous maps is homeomorphic to $c_{0}$. Topology Appl. 153: 2908-2921. 